\title{
Indigenizing Education through the Use of Music and Art in the Post- Secondary Classroom
}

\author{
Karen Favell \\ University of Manitob, Canada
}

\begin{abstract}
This study investigates Aboriginal student experiences in an Aboriginal transition program that was co-developed by the student-participants. Data was collected from participants in the study through a focus group, journals, and surveys. The results show that adding Aboriginal cultural activities to the curriculum improved the experience of students in the transition program. Students felt that their contributions were important and valued, that they learned more about their traditional culture, and that their contributions enhanced their experience in the program. Allowing Aboriginal students to participate in their own education empowers them and improves their overall educational experience.
\end{abstract}

\section{Introduction}

Post-secondary institutions have developed Aboriginal transition programs in order to meet the needs of Aboriginal students who may require further preparation before entering more advanced academic programs. In colleges, Aboriginal transition programs can lead to trades, paraprofessional programs, and diploma programs related in some way to Aboriginal people. Many Aboriginal students may have neither the required high school nor the required post-secondary courses for entrance into these professional programs [1], [2], and so need to first complete a transition program in order to increase their chances of being academically successful in their professional programs.

It is sometimes necessary for Aboriginal students at the post-secondary level to have an increased focus on academic preparation before entering professional programs such as Law or Medicine, para-professional programs such as dental assistant or teacher assistant, as well as other diplomas and certificates. A 2005 poll conducted by Aboriginal Affairs and Northern Development Canada (AANDC) found that most aboriginal students believe that the education they receive on reserve is insufficient [3]. This is because once they complete their education on reserve they feel they are about two grades behind students who attended public school, an opinion also shared by AANDC, according to Mendelson [3]. However, a comparison between First Nations and public schools is not necessarily straightforward. Several researchers [4-10] have noted that systemic inequities exist that privilege non-Aboriginal students over Aboriginal students, such as lack of Aboriginal cultural relevance in curriculum, marginalization of Aboriginal people in society and in curriculum, and failing to involve Aboriginal people in curriculum development. In addition, their education continues to have an assimilationist agenda.

According to Restoule [11], although both Aboriginal and non-Aboriginal policy-makers have addressed these issues in Aboriginal education for years, there continues to be systemic discrimination for Aboriginal students in mainstream education as well as in Aboriginal communities, one example being the chronic underfunding of First Nation schools across Canada [12], [13]. For example, AANDC capped funding for both secondary and post-secondary Aboriginal education in 1996, allowing for only a $2 \%$ increase per year [14]. This is despite data from the 2006 Census, which states that $50 \%$ of the Aboriginal population in Canada is under the age of 25 [15]. Government underfunding of programs impacts academic programming at the primary and secondary levels, and as a result, students who come to university or college from Aboriginal communities are not necessarily receiving the same level of academic preparation for post-secondary education as their nonAboriginal counterparts [1], [16]. Aboriginal students can greatly benefit from taking transition programs that offer basic courses in Science, Math, and Academic Writing, which help to ensure that they have the necessary skills to succeed in college or university. R. A. Malatest \& Associates [12] and Richardson and Blanchet-Cohen [17] suggest that while Aboriginal transition programs are meant to provide supports to students, both academic and personal, they should also be designed to create a safe, welcoming environment for students who are far from home and may have left home for the first time. 
One of the ways to create this welcoming environment is to include Aboriginal cultural activities within academic programming, according to Battiste, Bell, \& Findlay [18] and Newton [19], which has led to improved academic performance by Aboriginal students in previous studies [20-23]. The length of these transition programs ranges from six weeks to two years [24-25], and this poses a further problem when students in these programs apply for funding from AANDC. AANDC are more likely to fund students in degree programs, rather than in transition programs [20]. However, transition programs are important for the future success of Aboriginal students as they continue their education [18, 20]. According to Riecken et al. [9], in addition to contributing to student success, education that includes aspects of Aboriginal culture in curriculum has the ability to provide a transformative experience for students. This transformation occurs when Aboriginal students feel pride in their own culture [21], which is one of the goals of infusing Aboriginal curriculum with cultural content [7], [24].

As an Ojibway instructor, I believe that it is important to enhance Aboriginal programming at our college with traditional Aboriginal content. To this end, we began by offering an Aboriginal Music course to students in the College Studies program, which is an Aboriginal transition program at the college. This study examines the experiences and impressions of Aboriginal students who have taken the Aboriginal Music course as part of the transition program.

\section{Empowering Aboriginal Education}

Hampton [25] identifies five different meanings of the term "Aboriginal education", each of which has its primary use in North America at different times: traditional education (in ancestral culture), where the education of Aboriginal children was done in a traditional way; education for self-determination (which pre-dated residential schools and involved test schools in the southeastern United States); education for the purpose of assimilating Aboriginal students into mainstream society, education by Aboriginals (Aboriginal instructors, mainstream curriculum), and Aboriginal sui generis (unique, one-of-a-kind) education, in which Aboriginal content is taught using Aboriginal teaching methods. At the time, Hampton (1995) believed that Aboriginal education was and continues to be currently in the "education by Aboriginals" phase of Aboriginal education because there was yet to be an Aboriginal education system in which Aboriginal people control both content and delivery methods. This is problematic because Aboriginal people in Canada remain under the influence of the Indian Act and therefore must still follow AANDC directives as well as provincial regulations which still dictate how education is to be delivered, for Aboriginal and non-Aboriginal education systems alike. Unfortunately, the mainstream education system, according to Godlewska et al. [6], continues to imbed colonial values and beliefs into curriculum, and most Aboriginal educators are obligated to use this curriculum to teach Aboriginal students. Hampton [25] writes: "Because Western education seeks to indoctrinate Aboriginal children by substituting non-Aboriginal for Aboriginal knowledge, values, and identity, Western education is in content and structure antagonistic to Aboriginal people". However, Aboriginal education should incorporate Aboriginal content and ways of knowing, furthermore, Aboriginal students should be more directly involved with their own education.

In order to offer effective Aboriginal education, the current system would have to be completely re-designed. Rather than mainstream education being based primarily in mainstream culture with the addition of some Aboriginal content, Aboriginal education should instead be based in Aboriginal culture, with the addition of some mainstream content. Aboriginal students come into school with their own prior knowledge, skills, and interests, and these need to be accessed and utilized when developing or delivering curriculum [5]. If Aboriginal students were more involved in developing their own curriculum, they would have a deeper understanding and appreciation of their own education and have more ownership and control [6], [17], [18]. Although Aboriginal education remains under the control of government, Aboriginal people have been making attempts to change this relationship by making adaptations to the current education system so that it is more culturally relevant to Aboriginal students.

For example, Tatz [26], in a study involving Aboriginal Australians, suggests that an effective Aboriginal education system would have to be completely different from the current system because it would stop attempting to teach Aboriginal students the same content using the same methods as used with nonAboriginal students. Instead, an Aboriginal curriculum would reflect Aboriginal perspectives and focus on subject matter that is specific to Aboriginal people [17], [18], [27], not only in isolated units unrelated to the rest of the curriculum (treaties, land claims, and current Aboriginal experiences) or as one-day cultural awareness events. Curriculum and delivery should involve Aboriginal people to ensure that the voices of Aboriginal people are acknowledged and respected [18], [19], [23], 
[25]. Of course, some instructors of Aboriginal students will be non-Aboriginal, but these teachers must also learn how to deliver the content using Aboriginal methods [23], [27]. Aboriginal methods and perspectives must be meaningfully incorporated and have equal value to other approaches and perspectives used in the classroom, particularly when discussing historical and contemporary events that involve Aboriginal people [28, 29, 30]. Aboriginal communities must also be given the power to inform curriculum and pedagogy, instead of re-creating mainstream models of education and using these as the basis of Aboriginal education [7], [18], [19,].

Curriculum development and delivery would be done collaboratively by involving educators, elders, and content experts from the community, with complete control over budget, teaching staff, and curriculum [1618, [23]. The goal of Aboriginal education, according to Riecken et al. [9], would be to provide an exciting environment in which to learn by integrating Aboriginal culture and involving cultural instructors and elders. Providing an exciting learning environment would in turn lead to academic success for students, whose education would have far more cultural relevance than the current system provides.

\section{The Aboriginal Music Course}

The purpose of this study was to examine the experiences and impressions of Aboriginal students who participated in the Aboriginal Music course as part of their College Studies transition program. The fivemonth Aboriginal Music course was piloted in 2010 and this study of the course was conducted during the second offering of the course, which began in September 2011 and ended in January 2012.

The students in the Aboriginal Music course had the opportunity to engage in traditional Aboriginal activities such as the making of Aboriginal instruments, to attend traditional cultural events, such as pow-wows and sweatlodges, and to assist in the curriculum planning of the course. The following questions provide the foundation for this study.

1. Does adding an Aboriginal music course to regular college courses improve the experience of the students while they are enrolled in Aboriginal transition programs?

2. Does involving students in the development of curriculum improve their educational experience?

\section{Method}

\subsection{Setting}

The College Studies program is a ten-month transition program that is designed to give Aboriginal students the academic background necessary to succeed in a variety of academic programs at our college. The Aboriginal Music course was held for three hours every Friday afternoon from 1:00 to 4:00 pm. in the Aboriginal Student Centre.

The Centre is a large space designed to simultaneously accommodate students from all of the programs in Aboriginal Education for cultural events such as feasts and pipe ceremonies. In addition to musical performances in the Aboriginal Student Centre, our class also attended public performances off-campus in various locations. For example, students attended a three-day pow-wow in a large arena and they also attended musical performances in smaller venues around the city. When possible, we attended these events as a group, but we often had to meet at these events because they were held in the evenings or on the weekends. Most performances were held at the college.

I invited and received consent from 12 of the 15 students who were enrolled in the Aboriginal Music course. All of the students who consented participated in focus groups, completed surveys, and kept journals. I did not know which students had consented to participate in the study and which had not until the course was completed. I used data only from the students who had given their consent to participate in this study at the beginning of the course, but all students participated in all classroom activities whether or not they were participating in the study.

\subsection{Participants}

The participants in this study were students in a college transition program and were all high school graduates who came to the program from Aboriginal communities all over the province. Pseudonyms were given to each of the students in this study to ensure anonymity. Ethical review procedures for both The University of Western Ontario and the college were followed to ensure the safety of participants and that I met all ethical requirements of both of these institutions. 


\subsection{Procedure}

During the first class, students were told about the study, including my research questions and how I would be collecting data. The students were invited to participate in the study, but I made sure to inform students that their participation was not mandatory. I also informed students that I would be unaware of who would be participating and who would not because I had one of the secretaries administer and collect the consent forms. I never did know who among the students had agreed to participate in the study. I then had students collaboratively determine what styles of music and even which specific performers they would like to see in the class. In addition, students identified which traditional musical instruments they would like to make in the class. I had the students make these decisions because I wanted to allow students to infuse their perspective into the curriculum of the course.

The students identified musical performers from a variety of genres that they wanted to see in the class, and I accommodated them where possible. Some of the performers in the course included Indian City (country rock band), the Gaudry Boys (Metis fiddle music), and Wab Kinew (hip hop mixed with traditional hand drum singing). Students also had the opportunity to attend a pow-wow, which was a major cultural event held over three days. As well, students had the opportunity to participate in Aboriginal Music Week, which consisted of different concerts every night performed by innovative Aboriginal musicians such as Joey Stylez, an Aboriginal hip-hop artist, and the Electric Pow-Wow, which was traditional pow-wow music fused with hip hop music accompanied by a light show and held in a club. Students also participated in making hand drums and Aboriginal flutes in the course, both of which were facilitated by elders who provided cultural teachings as well as technical expertise.

In addition to watching musical performances and reflecting upon these experiences though weekly journals, students prepared presentations about various aspects of Aboriginal Music and demonstrated their own expertise as musicians and artists through performances in class. One of the students demonstrated his skills as a pow-wow grass dancer and other students demonstrated skills at Metis jigging and traditional crafts. These experiences likely helped to increase the self-confidence in all of the students because they saw how talented their Aboriginal peers in the class were - something that has been shown to increase student pride in themselves as Aboriginal people [9], [21], [30]. The students also conducted research about various aspects of Aboriginal music and the information they found was supplemented by material I provided. The students completed reflective journals about their experiences in the course each week.

\section{Findings}

The experiences of the students in the Aboriginal Music course were overwhelmingly positive. I organized the student responses to the journals, surveys, and the focus group into five main themes, which were: students enjoyed their experiences in the course, students found the course interesting, they learned more about Aboriginal culture, the impacts of the course upon their experiences in the overall college program, and the effects of participating in course development upon their experience of the program.

Students had fun in the Aboriginal music class and enjoyed the experiences they shared during class, such as watching performers or creating instruments. The students found tours we took during the class interesting, as well as the exposure to traditional music, such as powwows. Many of the students came from a Christian background and had little to no prior contact with aspects of Aboriginal traditional culture. The students found that participating in the Aboriginal Music course made them feel proud to Aboriginal and this had a positive impact upon their experiences in their overall program. Many of the students looked forward to the course, which was on Friday afternoons, and characterized it as something they looked forward to all week. Students reported that participating in curriculum development was a positive experience for them because it made the class more interactive, they felt more involved, and they felt that they were connected to the larger Aboriginal community.

\section{Conclusions}

In order to have culturally relevant education, curriculum developers must involve the local Aboriginal community. This can be done through partnerships among academic institutions, instructors of Aboriginal students, and Aboriginal communities [28-31]. My study involved members of the Aboriginal community through partnerships with Aboriginal organizations and performances and workshops facilitated by local Aboriginal musicians and artists.

One of the ways to ensure students have positive educational experiences in their program is to involve them in the development of curriculum [33-36]. 
Students in my study assisted in the curriculum development of their program by determining which musicians they would like to see, musical events in which they would like to participate, and the opportunity to give feedback to the instructor.

This particular Aboriginal Music course improved the experience of the Aboriginal students who were in the course, made them feel proud to be Aboriginal, and made them feel that their contributions to their learning were important and valued. As well, the Aboriginal community was involved in the program through the Aboriginal musicians and cultural teachers who came to the class during the course. The students also received credit for the course, which they used toward attaining their College Studies certificate, which led to other diplomas and degrees at the college.

\section{Future Research}

Most of the projects I have referred to in this study, including my own, are limited in scope. Most of the time, as noted by Bouvier and Karlenzig [20], Richardson and Blanchet-Cohen [17], and Robertson [37], Aboriginal content is added to existing programming by inserting one Aboriginal-focused course into mainstream curriculum. The Aboriginal Music course is an example of this method of incorporating Aboriginal curriculum into existing programming, which is not ideal. The Aboriginal Music course gives students the opportunity to listen to Aboriginal music played by Aboriginal musicians, to construct and play their own instruments, and to learn more about Aboriginal culture. Some of the students may have enjoyed the course because listening to the music might have given them glimpses into their past as Aboriginal people, but also hope for what Aboriginal people can become now and in the future. Aboriginal music is an important element in Aboriginal education because it helps students to connect to and understand more about Aboriginal culture. Including Aboriginal music in the curriculum and allowing students to participate in developing their own curriculum helps students to feel proud of who they are as Aboriginal people.

\section{References}

[1] Hull, J., Phillips, R., \& Polyzoi, E. (1995). Indian control and delivery of special education services to students in bandoperated schools in Manitoba. Journal of Educational Research, 4(1), 36-62.
[2] National Aboriginal Health Organization. (2003). A listing of Aboriginal health careers: Educational and training opportunities. Retrieved from http://www.naho.ca (Access Date: 5 January, 2012).

[3] Mendelson, M. (2006). Aboriginal peoples and postsecondary education in Canada. Ottawa: The Caledon Institute of Social Policy.

[4] Agbo, S. (2002). Unstated features of cultural deprivation or discontinuity: Culture standards for administrators and teachers of Aboriginal students [Mohawk education curriculum development project]. Journal of Educational Administration and Foundations, 16(2).

[5] Cajete, G. (1994). Look to the mountain: An ecology of Indigenous education. Durango, CO: Kivaki Press.

[6] Godlewska, A., Moore, J, \& Bednasek, C. D. (2010). Cultivating ignorance of Aboriginal realities. The Canadian Geographer, 54(4), 417-440.

[7] Goulet, L. (2001). Two teachers of Aboriginal students: Effective practice in sociohistorical realities. Canadian Journal of Native Education, 25(1), 68-82.

[8] Kirkness, V. J. (1998). Our peoples' education: Cut the shackles; cut the crap; cut the mustard. Journal of Native Education, 22(1), 10-15.

[9] Riecken, T.; Conibear, F.; Michel, C.; Lyall, J.; Scott, T.; Tanaka, M.; Stewart, S.; Riecken, J., \& Strong-Wilson, T. (2006). Resistance through re-presenting culture: Aboriginal student filmmakers and a participatory action research project on health and wellness. Canadian Journal of Education, 29(1), 265-286.

[10] Sykes, H. (2008). Narratives in Aboriginal, history and place-based education. Curriculum Inquiry, 38(5), 541-544.

[11] Restoule, J. (2008). Aboriginal education and selfgovernment: Assessing success and identifying the challenges to restoring Aboriginal jurisdiction for education. In Y.D. Belanger (Ed.), Aboriginal self-government in Canada: Current trends and issues (pp. 373-392). Saskatoon: Purich Publishing Limited.

[12] R. A. Malatest \& Associates. (2005). Best practices in enhancing Aboriginal participation in post-secondary education: Canadian and international perspectives. Retrieved from http://www.cprn.org. (Access Date: 13 March, 2012).

[13] Aboriginal University Education Roundtable (2007). University of Winnipeg, Winnipeg, Manitoba.

[14] First Nations Education Council (2010). Towards the financial accessibility of lifelong learning: A First Nations perspective. Presentation made to Advisory Committee on the 
Financial Accessibility of Education. Government of Quebec. Wendake, Quebec. Retrieved from http://www.cepn-fnec.com.

[15] Statistics Canada (2012). Aboriginal Peoples Survey 2012 - Education and Employment. Retrieved from http://www23.statcan.gc.ca.

[16] Hill, S. M. (2007). Best practices to recruit mature Aboriginal students to medicine. Retrieved from www.ipacamic.org.

[17] Richardson, C., \& Blanchet-Cohen, N. (2000). Postsecondary educational programs for Aboriginal peoples: Achievements and issues. Canadian Journal of Native Education, 24(2), 169-184.

[18] Battiste, M., Bell, L., \& Findlay, L. M. (2002). Decolonizing education in Canadian universities: An interdisciplinary, international, Indigenous research project. Canadian Journal of Native Education, 26(2), 82-95.

[19] Newton, P. L. (2007). Northeast Saskatchewan Aboriginal students' perceptions of their distance education experiences and the relationship to their Aboriginal culture. Athabasca: Athabasca University.

[20] Bouvier, R., \& Karlenzig, B. (2006). Accountability and Aboriginal education: Dilemmas, promises, and challenges. Our Schools, Our Selves, 15(3), 15-33.

[21] Brade, C. R. M., Duncan, K. A., \& Sokal, L. (2003). The path to education in a Canadian Aboriginal context. Canadian Journal of Native Education, 27(2), 235-248.

[22] Evans, M., McDonald, J., \& Nyce, D. (1999). Acting across boundaries in Aboriginal curriculum development: Examples from northern British Columbia. Canadian Journal of Native Education, 23(2), 190-205.

[23] Lee, T. S. (2007). Connecting academics, Indigenous knowledge, and commitment to community: High school students' perceptions of a community-based education. Canadian Journal of Native Education, 30(2), 196-216.

[24] VanEvery-Albert, C. M. (2008). An exploration of Indigenousness in the Western university institution. Canadian Journal of Native Education, 31(1), 41-55.

[25] Hampton, E. (1995). Towards a redefinition of Indian education. In M. Battiste \& J. Barman (Eds.), First Nations education in Canada: The circle unfolds, pp. 5-46. Vancouver: University of British Columbia Press.

[26] Tatz, C. (2009). Aboriginal education, again. Australian Aboriginal Studies, 2009(1), 92-96.
[27] Hookimaw-Witt, J. (1998). Any changes since residential school? Canadian Journal of Native Education, 22(2), 159170.

[28] Kennedy, M. C. (2009). Earthsongs: Indigenous ways of teaching and learning. International Journal of Music Education, 27(2), 169-182.

[29] Antone, E. M. (2000). Empowering Aboriginal voice in Aboriginal education. Canadian Journal of Native Education, 24(2), 92-101.

[30] Corbiere, A. I. (2000). Reconciling epistemological orientations: Toward a wholistic Nishnaabe (Ojibwa/Odawa/Potowatomi) education. Canadian Journal of Native Education, 24(2), 113-119.

[31] Mahara, M. S., Duncan, S. M., Whyte, N., \& Brown, J. It takes a community to raise a nurse: Educating for culturally safe practice with Aboriginal peoples. International Journal of Nursing Education Scholarship, 8(1), 1-13.

[32] Price, R., \& Burtch, B. (2010). Degree completion for Aboriginal people in British Columbia: A case study. Canadian Journal of University Continuing Education, 36(1), 1-17.

[33] Brinegar, K., \& Bishop, P. A. (2011). Student learning and engagement in the context of curriculum integration. Middle Grades Research Journal, 6(4), 207-222.

[34] Cook-Sather, A. (2011). Layered learning: Student consultants deepening classroom and life lessons. Educational Action Research, 19(1), 41-57.

[35] Gleixner, S., Douglas, E., \& Graeve, O. (2007). Prime modules: Teaching introduction to materials engineering in the context of modern technologies. Paper presented at the meeting of the American Society for Engineering Education, 24-27 June, 2007, Honululu, HI.

[36] Oliver-Hoyo, M., and Allen, D. (2005). Attitudinal effects of a student-centered active learning environment. Chemical Education Research, 82, 944-949.

[37] Robertson, H. (2003). Decolonizing schools. Phi Delta Kappan, 84(7), 552-553. 